\title{
An alternative strategy to explore missing proteins with low molecular weight
}

\author{
Zhilong Lin ${ }^{1,2 \#}$,Yuanliang Zhang ${ }^{1,2 \#}$, Huozhen $\operatorname{Pan}^{1,2}$, Piliang $\mathrm{Hao}^{3}$, Siqi $\mathrm{Li}^{1,2}$, Yanbin $\mathrm{He}^{1,2}$, \\ Huanming Yang ${ }^{1,4}$, Siqi Liu ${ }^{1,2^{*}}$, Yan Ren ${ }^{1,2^{*}}$
}

${ }^{1}$ BGI-Shenzhen, Beishan Industrial Zone $11^{\text {th }}$ building, Yantian District, Shenzhen, Guangdong, 518083, China

${ }^{2}$ Clinical laboratory of BGI Health, BGI-Shenzhen, Shenzhen 518083, China

${ }^{3}$ School of Life Science and Technology, ShanghaiTech University, 393 Middle Huaxia Road, Shanghai 201210, China

${ }^{4}$ James D. Watson Institute of Genome Sciences, Hangzhou 310058, China

\# The authors have the equal contributions for this work.

*To whom correspondence should be addressed:

Siqi Liu, BGI-Shenzhen, Beishan Industrial Zone $11^{\text {th }}$ building, Yantian District, Shenzhen, Guangdong, 518083, China. Tel: 86-755-36307403; E-mail: siqiliu@genomics.cn

Yan Ren, BGI-Shenzhen, Beishan Industrial Zone $11^{\text {th }}$ building, Yantian District, Shenzhen, Guangdong, 518083, China. Tel: 86-755-36307403; E-mail: reny@genomics.cn

\section{Contents}

Supplementary Figure S1. 
Supplementary Figure S1. The labeled spectra of all the identified unique peptides for 4 MPs.

Q6NT89, Peptide Sequence: SALGLGGCVPWGAGR, C8-Carbamidomethyl (57.02146 Da)

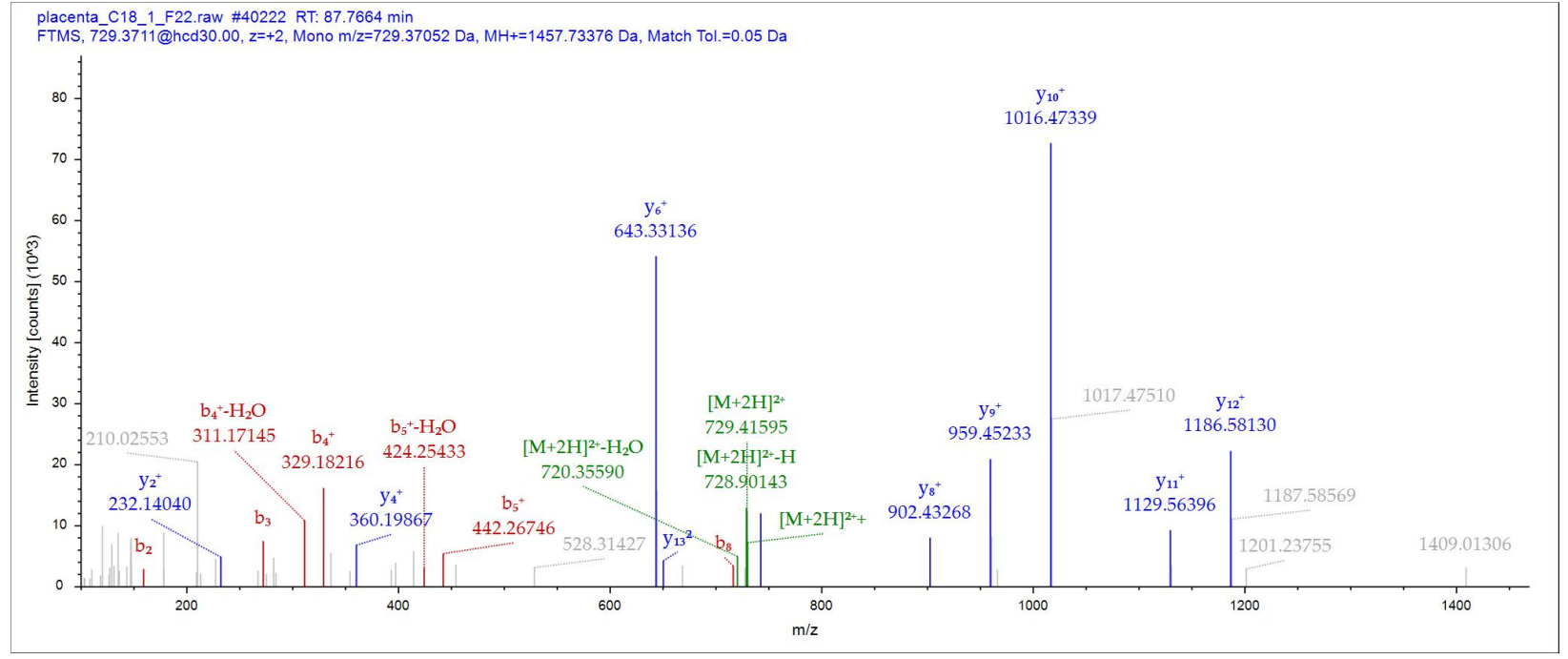

Q6NT89, Peptide Sequence: RGHGPEPDSPFR

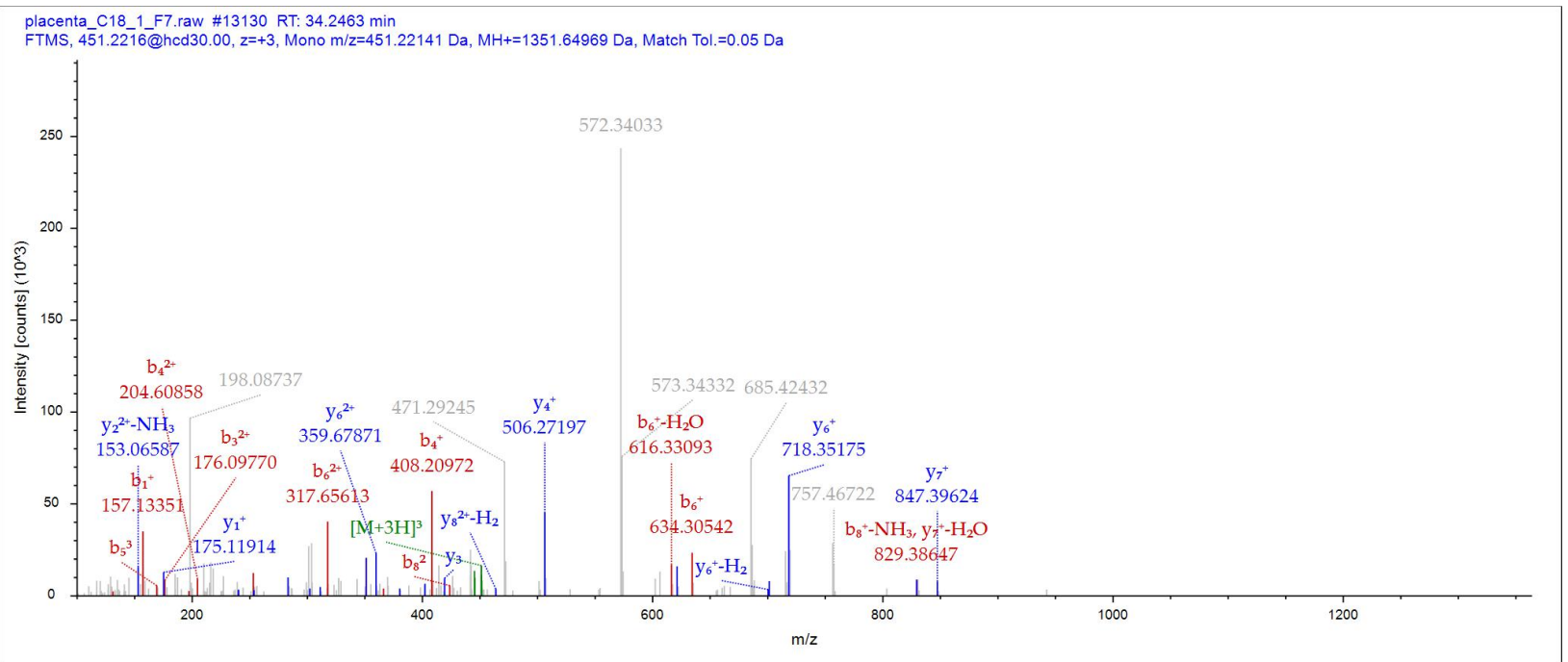


A0A183, Peptide Sequence: SNPCLAPYSTPCGAPHSEGCHSSSQRPEVQKPR, C4-Carbamidomethyl (57.02146 Da), C12-Carbamidomethyl (57.02146 Da), C20-Carbamidomethyl (57.02146 Da)

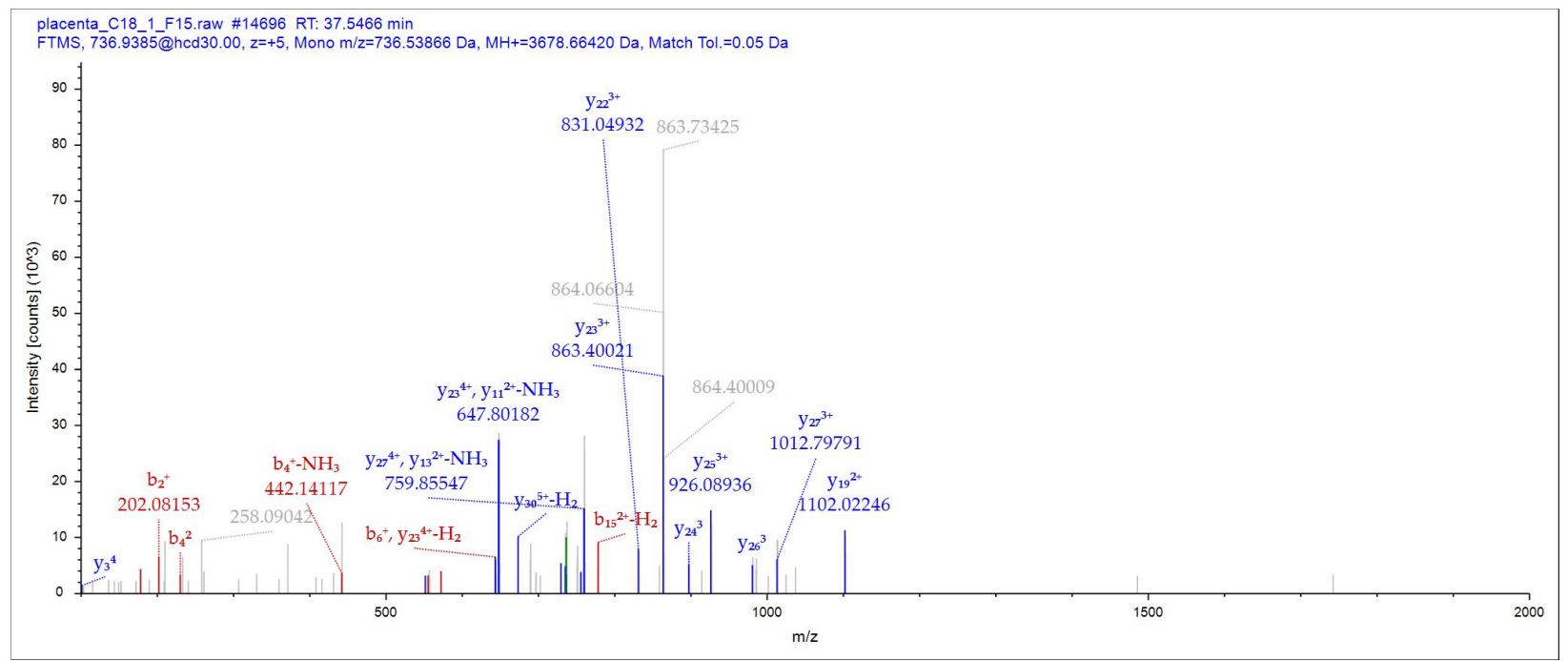

A0A183, Peptide Sequence: QQSWKPPNVPK

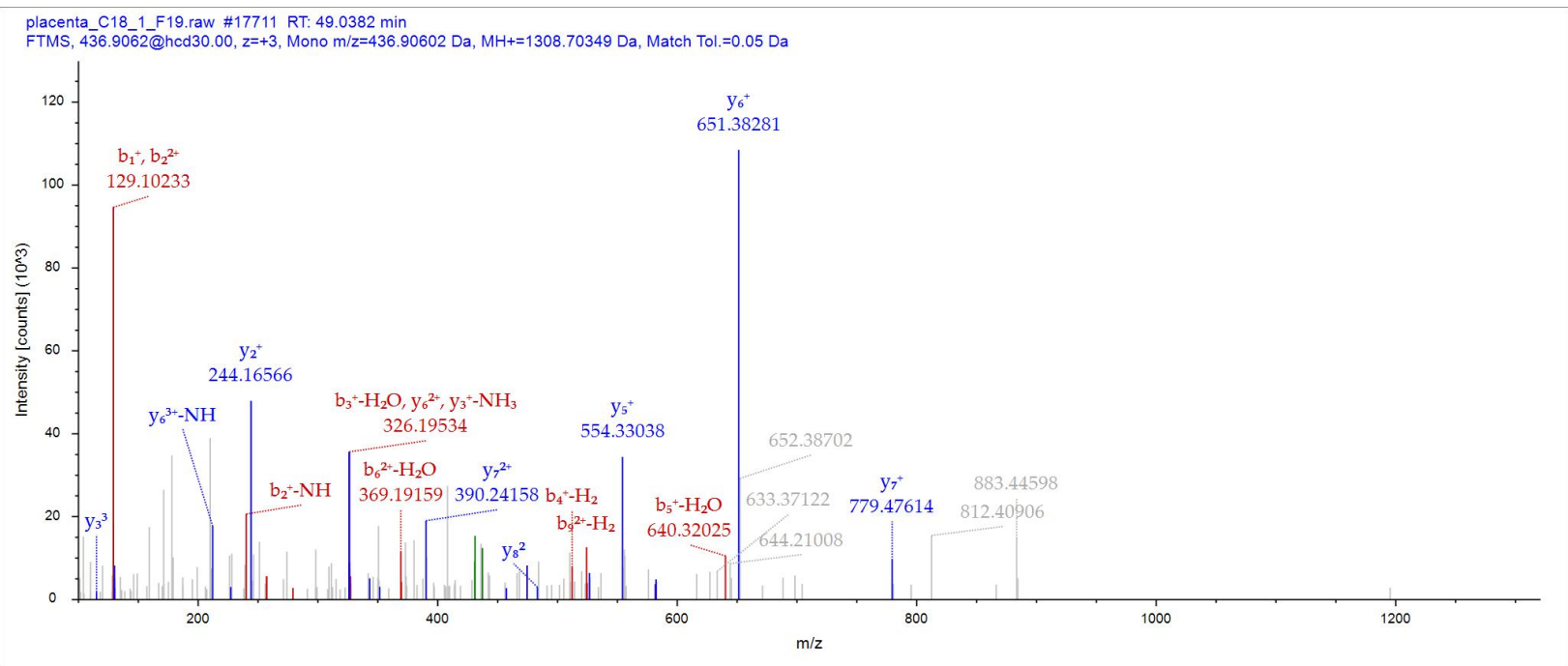


Q5DID0, Peptide Sequence: VADVSTLLGDIAK

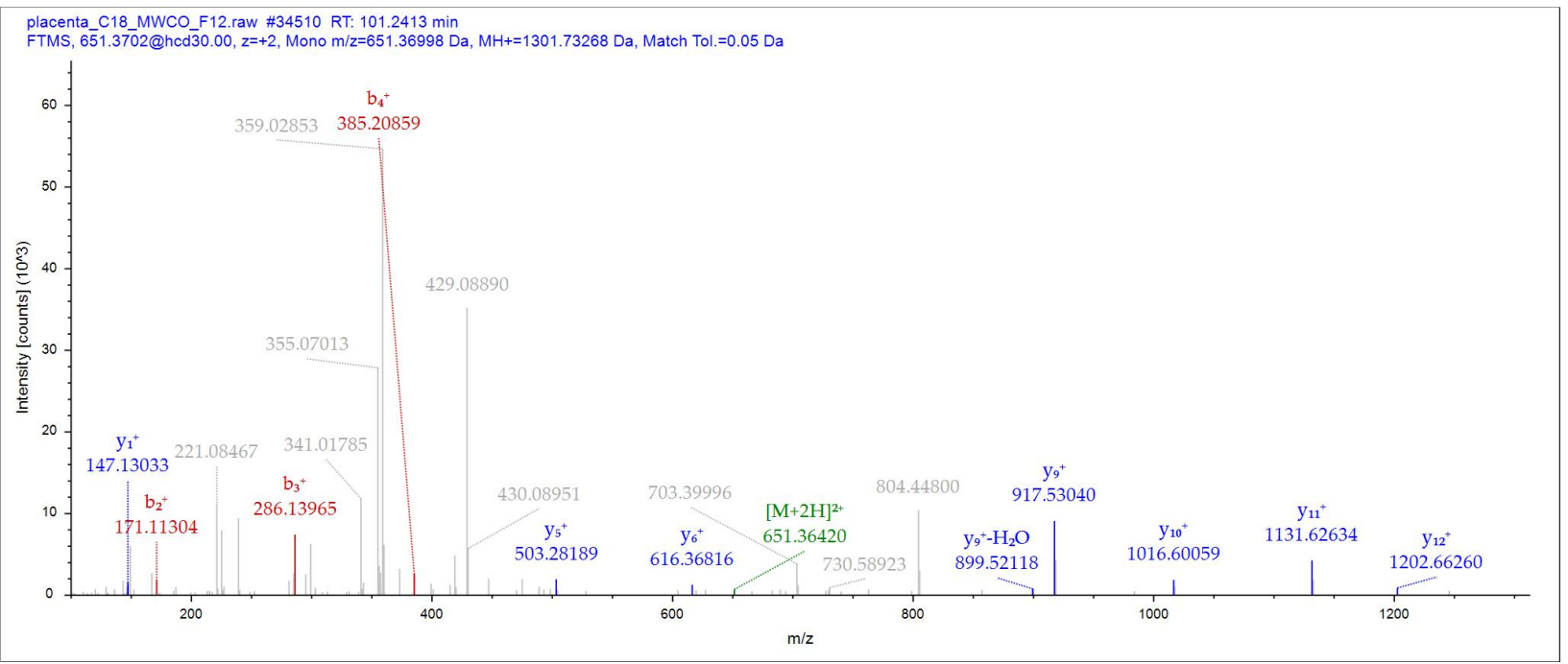

\section{Q5DID0, Peptide Sequence: AVAGLEAGVLYR}

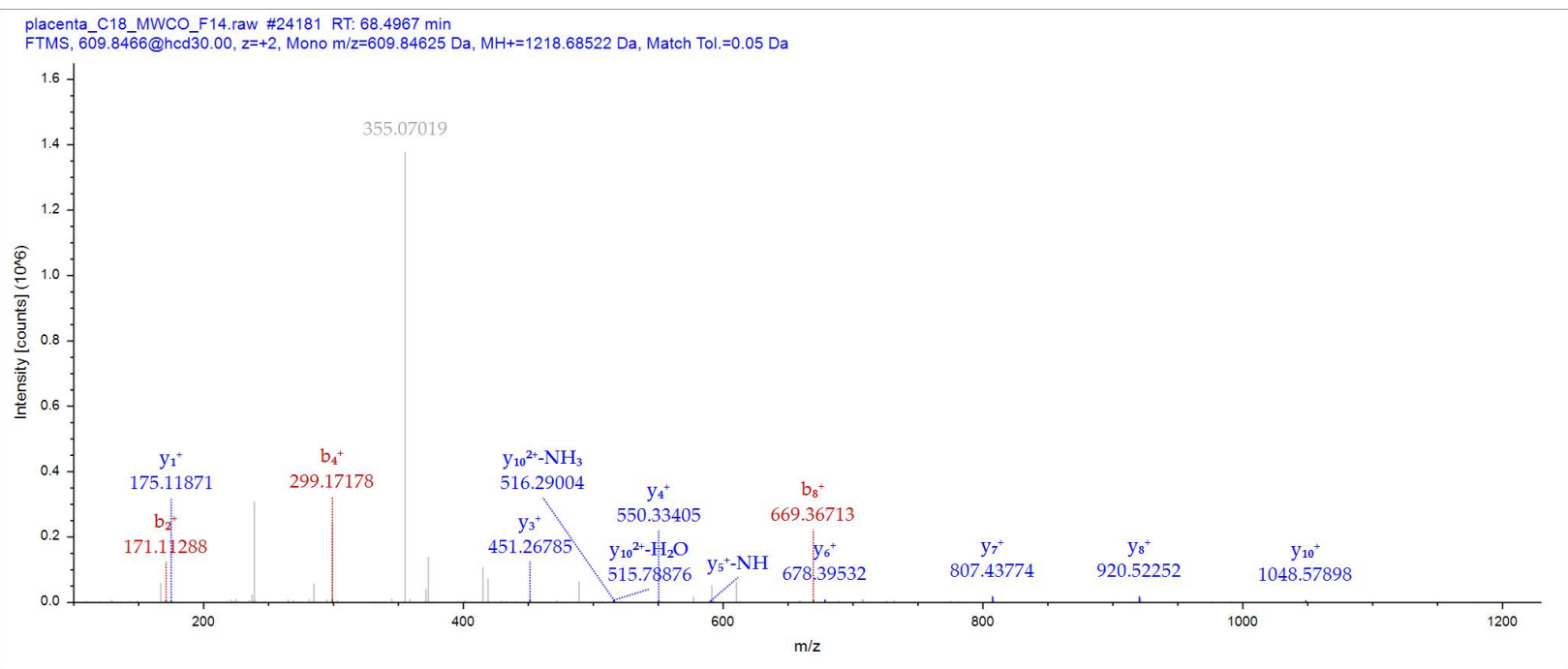


Q6UWQ7, Peptide Sequence: PAGSEPWLCQPAPR, C9-Carbamidomethyl (57.02146 Da)

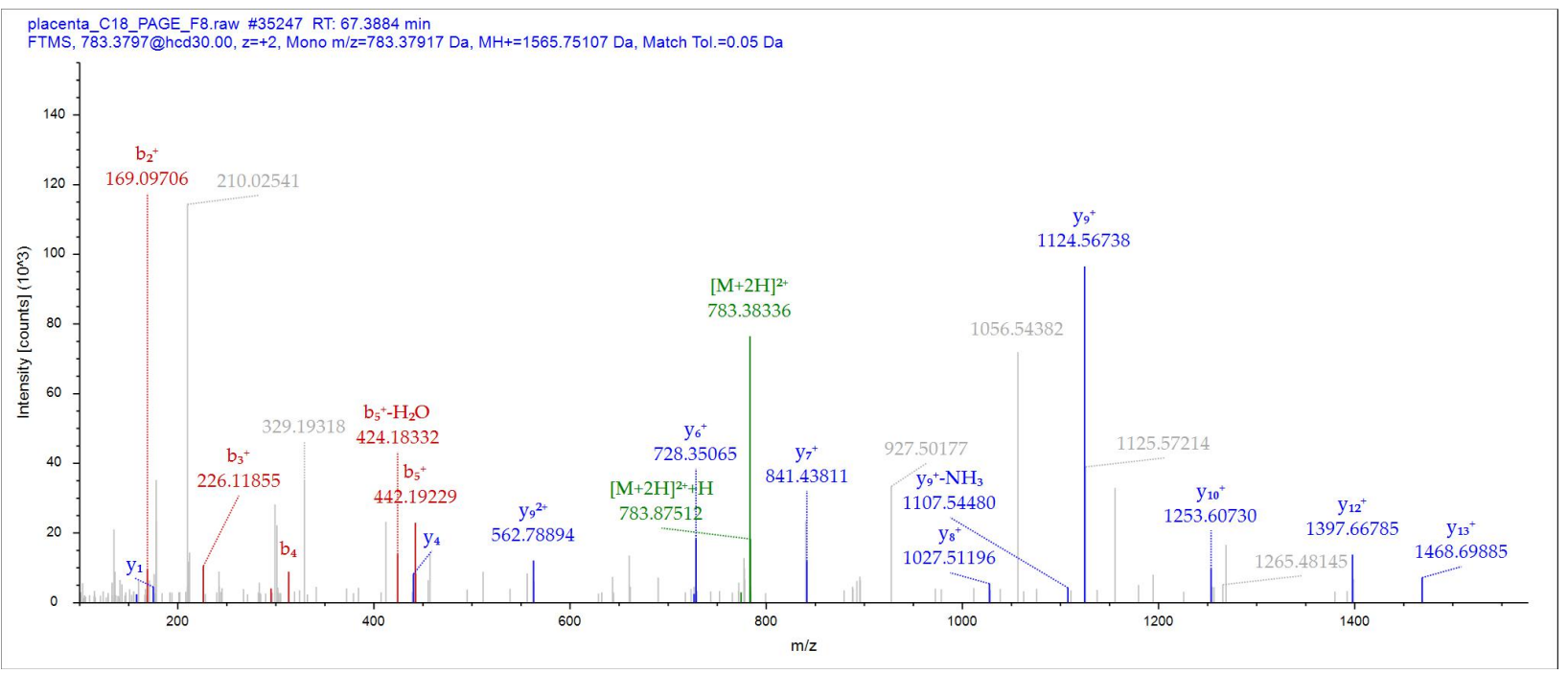

Q6UWQ7, Peptide Sequence: VQGVNSQCHSSPISSK, C8-Carbamidomethyl (57.02146 Da)

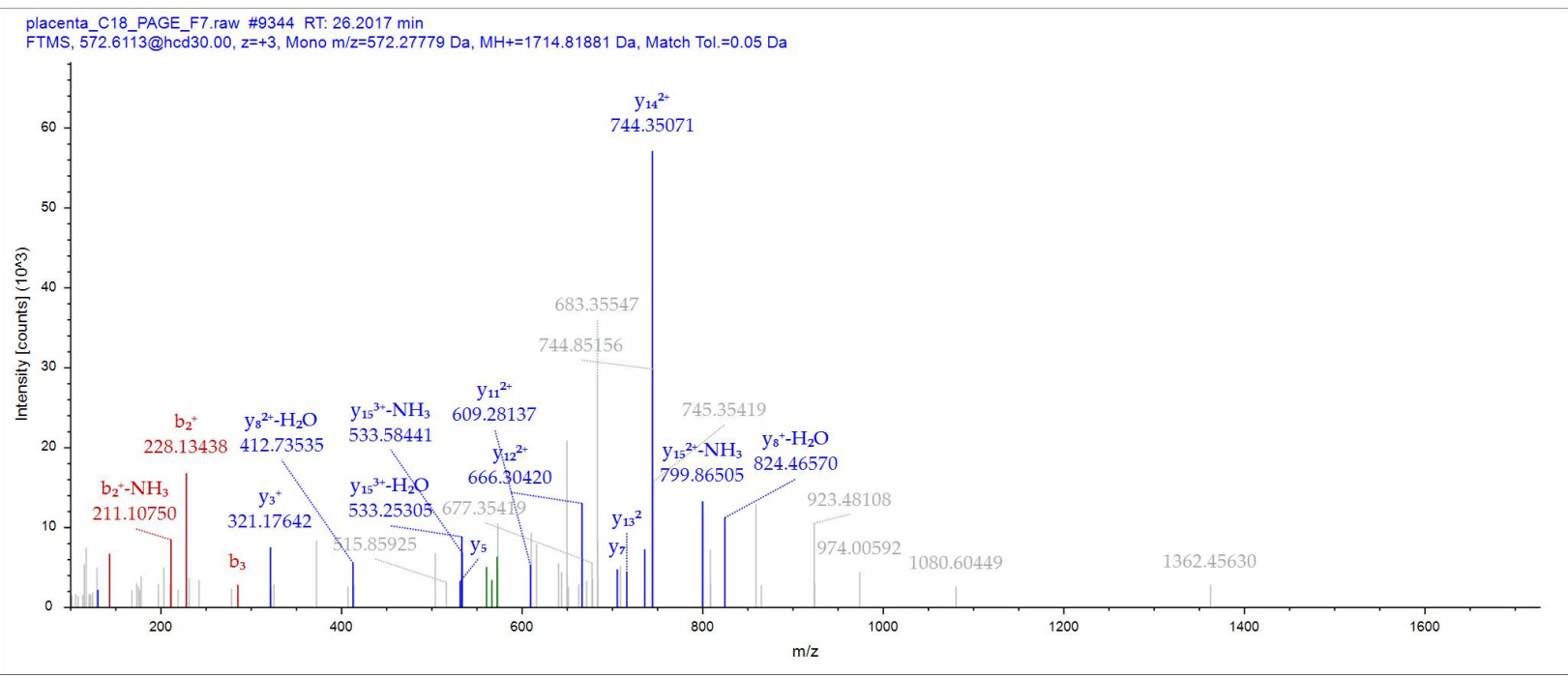


Supplementary Figure S2. The comparison of RT and fragment abundance pattern for the native peptides in human placental tissue and synthetic peptides from 4 MPs identified in PRM assay.

Q6NT89 SALGLGGCVPWGAGR
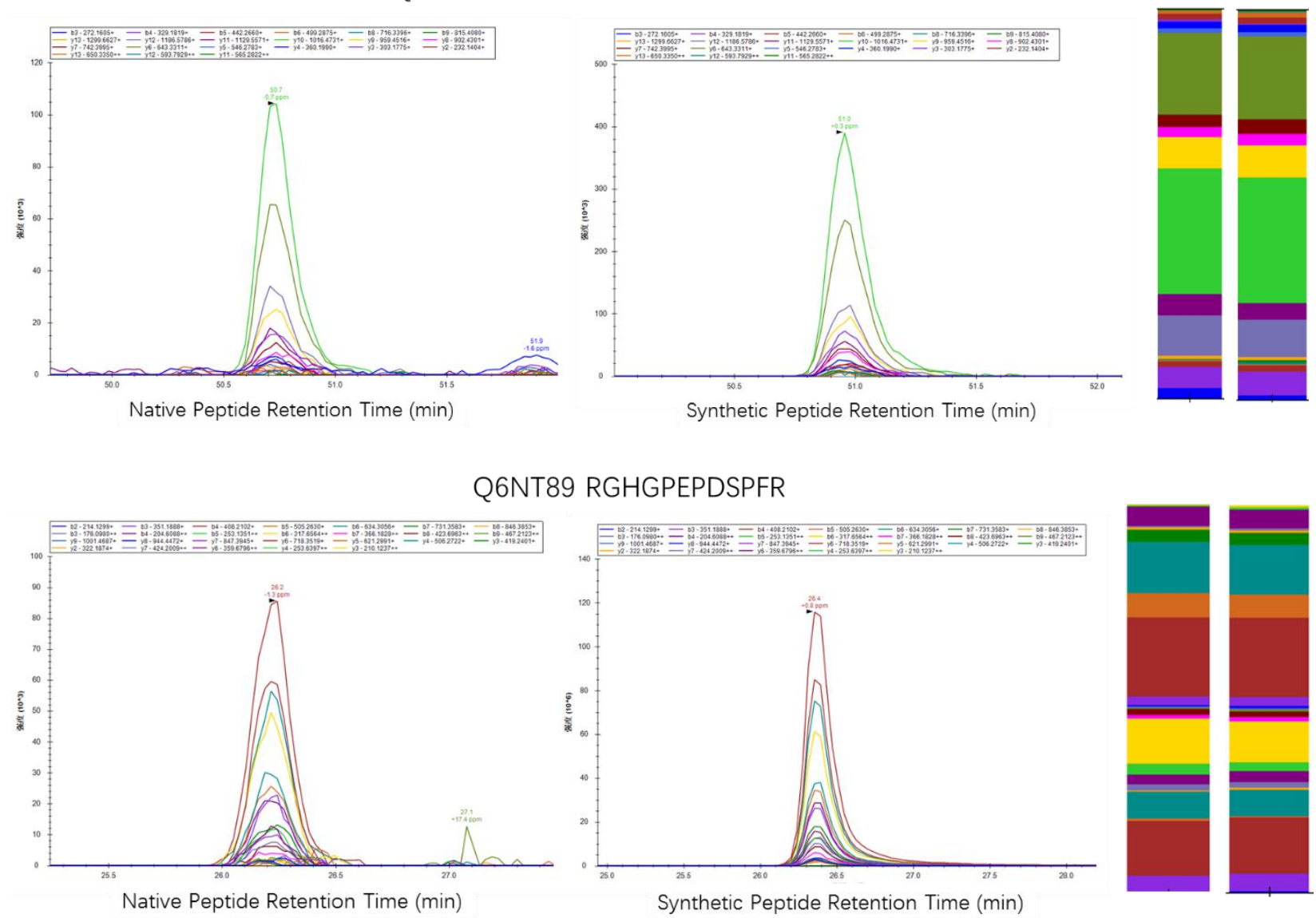

A0A183 SNPCLAPYSTPCGAPHSEGCHSSSQRPEVQKPR
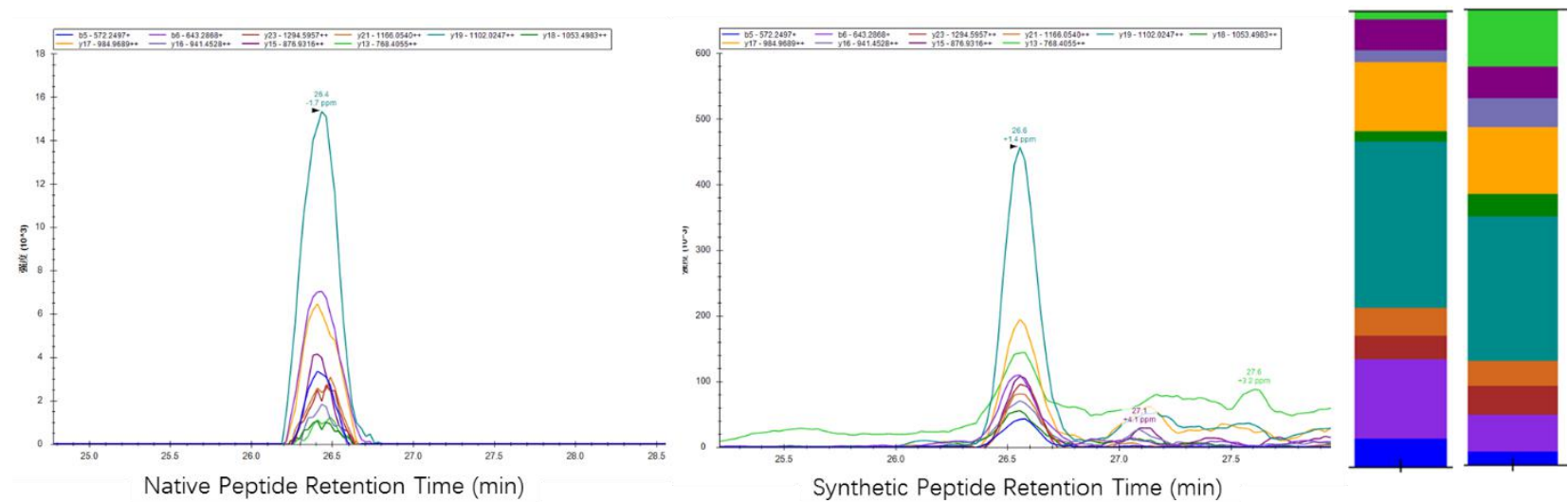
A0A183 QQSWKPPNVPK
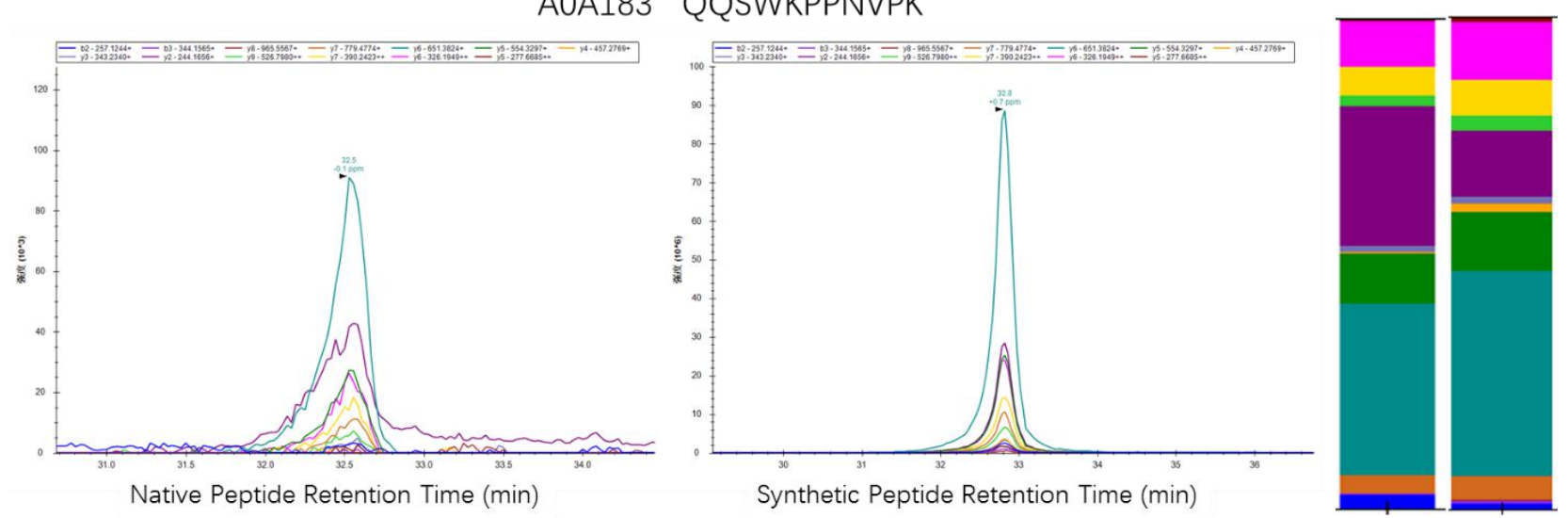

Q6UWQ7 PAGSEPWLCQPAPR
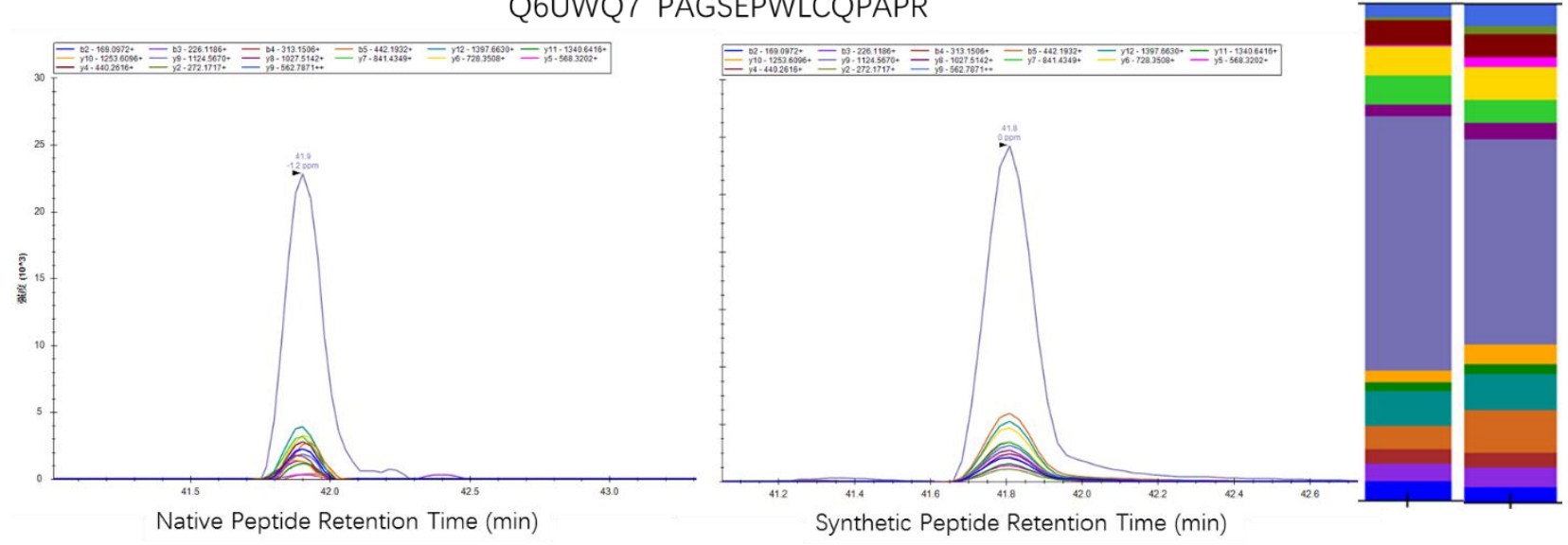

Q6UWQ7 VQGVNSQCHSSPISSK
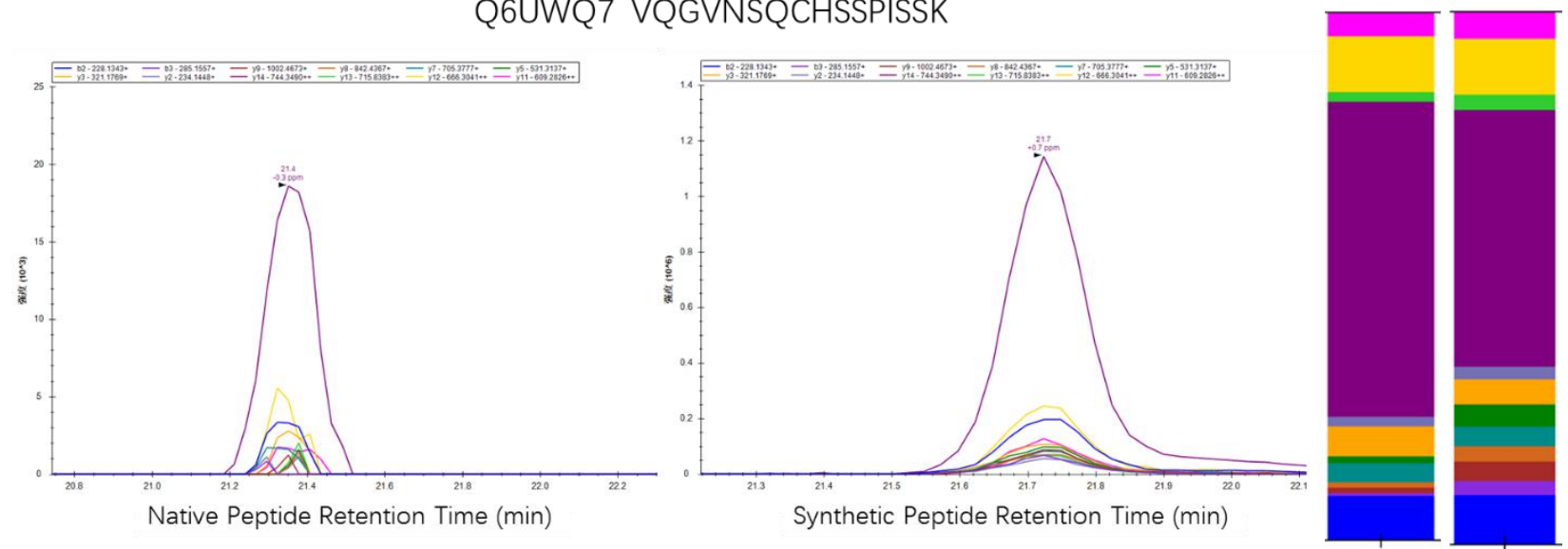